\title{
Problems Immigrants Face In Host Countries
}

\author{
Jabr Almutairi, Kingston University Of London, United Kingdom
}

\begin{abstract}
This study aimed to investigate the problems immigrants face in their host countries when dealing with native inhabitants, and to understand the effect of gender, age, and educational level on these problems. The sample for the study consisted of 150 immigrants working in Saudi Arabia. Means, standard deviations, and t-tests were used to analyze the results. The results showed that there are statistically significant differences in the problems that immigrants working in Saudi Arabia face. They also showed that there are statistically significant differences at $(\alpha=0.05)$ in the problems immigrants face owing to the gender variable, and statistically significant differences at $(\alpha=0.05)$ in the problems immigrants face owing to age and educational level.
\end{abstract}

Keywords: Host Country; Immigrants; Immigration

\section{INTRODUCTION}

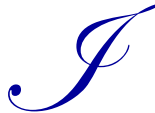

mmigrating to a new country is a long journey and an endless process involving both adaptation and acceptance. People who come from rural areas are accustomed to a simple society where everyone has a place in the community and no one is a stranger. Often, these people are thrust into a fast, impersonal, urban society that can be confusing and overwhelming. Immigrants generally have little or no preparation for the challenges they will face with respect to their traditional value systems. Both adult and child immigrants face cultural challenges: adults through daily interactions and children through the school system.

Family ties and deep friendships are frequently severed during immigration. Immigrants often lack the required social resources to support them through new experiences and difficulties in a new country. Feelings of loneliness and isolation are quite common, as newcomers grapple with a new environment as well as settlement issues.

Immigrants often have special skills that go unrecognized. A lack of fluency in Arabic and a lack of Saudi experience often lead to the acceptance of positions of lower stature. The struggle to become established frequently leads to the decision to have the mother enter the work force. This brings about a change in roles and added pressure for the mother.

Children come to have power over their non-Arabic speaking parents and grandparents as they learn Arabic and control the communication with their school and with the surrounding Arabic-speaking communities. They communicate to their parents what they want their parents to know and hear. Grandparents may find their traditional authority questioned by their children and challenged by their grandchildren. They often feel useless, lonely, and isolated. They find themselves entirely dependent on their children, with only a few meaningful activities to engage in.

The family is thrust into a new society where its members' social status may change. Consequently, members develop a need to establish and prove for themselves. As the children begin to assimilate into their new society, many lose fluency in their ethnic language while the adults fail to learn Arabic. Effective communication no longer exists between the children, parents, and grandparents. Often, a feeling of distance develops as children become better educated than their parents are. Some children become ashamed of their family and heritage. 
Moreover, visible minorities in our society are sometimes faced with discrimination, being misunderstood, and prejudice. This negativity, aggravated by a potentially depressed economy, can sometimes turn immigrants into scapegoats. As in any society, more established groups are usually suspicious of newcomers.

Many immigrants successfully cope with these challenges, but there are others who do not have the inner resources or experience to deal effectively with them. We, as good hosts, have a responsibility to assist those who need support in successfully integrating. By providing support services, we not only strengthen the family and our society but can also "head off" the development of major adjustment problems. In addition, we can invite and facilitate immigrant contributions to Saudi society. Here, we have an opportunity to show the world how different races and cultures can live, work, and play together in peace and contentment. What a hopeful and exciting challenge for all of us!

\section{Significance of the Study}

Most immigrants to Saudi Arabia stay, establish a living, and raise children in this country. Despite cultural conflicts, language barriers, or marginalization, most immigrants continue to find that Saudi Arabia is a land with more opportunity than their homeland, and they draw on all their tangible and intangible resources to survive here.

Among the many traumas of the emigration-immigration process is culture shock in an alien environment-language, social structures, norms, expectations, and values substantially differ from those that have been elemental to the immigrants' understanding of themselves. In the United States, well-understood roles and relationships can change and established patterns of interaction may be questioned. When immigrants have the psychological capability to cope with these as well as other stresses of relocating to an unfamiliar culture, they are more likely to adjust and control the direction of their lives. On the other hand, they may experience post-traumatic stress disorder, as do many refugees. Without sufficient and appropriate social and emotional support, including possible therapy, they may fail to find the immigration experience satisfactory, remaining unhappy, resenting their lives in the new land, pining for their familiar homeland and culture, and, occasionally, engaging in socially inappropriate and dysfunctional behaviors (Segal, 2002). The immigrant, therefore, not only needs social work skills and be culturally competent, but must also understand the breadth and the depth of the immigration experience.

\section{Statement of the Problem}

It usually takes years to adapt to the new living environment. Many immigrants gradually rebuild their lives and become very successful in their new country. However, some of them, particularly older people, keep struggling for the rest of their lives because they do not have the skills, experience, and flexibility to cope with major changes.

To be accepted into a new society, normally, newcomers have to change their thinking, behavior, habits, social norms, and their former way of life. We, in Saudi, can help them by understanding their struggles and assisting them in settling. By doing so, we will facilitate their contribution to our society. Immigrants face different challenges, and this research attempts to shed light on these challenges.

\section{Purpose of the Study}

The purpose of this study is to investigate the problems that immigrants working in service companies in $\mathrm{Al}$ Riyadh in Saudi Arabia face from their own perspectives, and to understand the effect of the workers' gender, age, and education on their perspective.

\section{Questions of the study}

- What are the attitudes of the immigrant workers in service companies in Al Riyadh towards the problems they are facing in the host country?

- Are there any statistically significant differences in the attitudes of the immigrant workers in service companies in Al Riyadh towards the problems they are facing owing to their gender (male, female)? 
- $\quad$ Are there any statistically significant differences in the attitudes of the immigrant workers in service companies in Al Riyadh towards the challenges they are facing owing to their age (less than 30 years, 30 years and above)?

- $\quad$ Are there any statistically significant differences in the attitudes of immigrant workers in service companies in Al Riyadh towards the problems they are facing owing to their educational level (high school, bachelor's degree)?

\section{Definition of Operational Terms}

Immigrant: A person who leaves one country to settle permanently in another. In our study, it means people who move to Saudi Arabia seeking job opportunities.

Host Country: A nation in which representatives or organizations of another state are present on a government invitation and/or international agreement.

\section{Limitations of the study}

This study is limited to the immigrants working in three service companies in Al Riyadh, Saudi Arabia.

\section{LITERATURE REVIEW}

Recent research in Europe has started emphasizing the importance of self-employment for immigrant and other excluded groups, not only in simple labor market terms but also as a self-empowerment strategy (Kupferberg, 2003; Apitzsch, 2003). Even though exclusion from the labor market is often the original motivation for selfemployment (for example, 25-30\% of ethnic entrepreneurs in Sweden had previously been unemployed (Alund, 2003)), the gains from setting up one's own business extend further. More claims on resources, and a strengthened negotiating position in the local space are important gains for those formerly considered to be second class citizens (Kupferberg, 2003), despite the fact that "path-dependency" (i.e., previous labor market situation) might determine the success or failure of the businesses themselves. Thus, for marginalized immigrants, ethnic entrepreneurship is as much to do with social integration as it is with making money from business activities; thus, the failure of a new business would not necessarily mean complete failure of the venture.

Koff (2002), looking at immigrants in Italy and France, tries to operationalize an empirical and theoretical challenge to much of the existing literature on immigrant integration. He takes as his starting point the idea that immigrants are not passive recipients of integration policies or weak social actors overwhelmed by the host country's structures and institutions. Rather, Koff posits that immigrants are rational political actors competing for a "just" distribution of resources, albeit within settings of varying ideologies and political cultures. This mesoanalysis, conducted on a city level, then tries to address the interaction of rationality, institutions, and cultural variables.

Another approach taken recently is the one adopted by Alexander (2003). As in much of the recent literature, he looks at policy at the local level and proposes a typology of host-stranger relations drawn from empirical material covering 25 cities, including Athens, Rome, Turin, Barcelona, Marseilles, Lille, and Tel-Aviv. His typology is, to a great extent, explicative of the older nation-state models of "guest worker," "assimilations," and "pluralist," with the addition of a new category that he names "transient." It is this category of "non-policy" that is of interest, since it is derived from the literature on Amsterdam in the 1960s, Rome in the 1980s, Tel-Aviv in the 1990s, and contemporary Athens. This transient attitude, he claims, is typical of local authorities in the first phase of labor migration, when the immigrant population is small and many immigrants are undocumented. Migrant workers are regarded as a transient phenomenon and the responsibility of the nation state; avoiding responsibility characterizes the local state, although some "street-level bureaucrats" may have a radically different view from the official one (Alexander, 2003). The (non-) strategy of the local state is to ignore migrant associations and blackeconomy activity; to allow migrant children access to schools and healthcare on an ad hoc basis; to ignore ad hoc places of worship, housing issues, and ethnic enclaves; and to treat migrants as a public security problem when necessary. The policy stance is essentially reactive and limited to specific crises; clearly, it is unsustainable over an extended period and will ultimately shift to another more goal-oriented stance. 
Vermeulen (2004) identifies three major dimensions of integration: structural, socio-cultural, and identity. The central goal of the first is equality of opportunity, namely equal access to education, housing, employment, and the political system. The second (socio-cultural), which he considers to be more controversial, addresses the choice of homogeneity versus heterogeneity. This policy choice can lead to pluralist toleration or multicultural social order, as compared with assimilation or non-tolerance of cultural and ethnic difference.

There are, of course, many possible varieties of this mix of homogeneity versus heterogeneity: few European countries are completely intolerant of ethnic differences, or completely accepting of all differences. The third dimension-identity - is linked with the second, but focused on inclusion versus exclusion. A good example is religion: acceptance of Islam as a religion of the country concerned would be indicative of inclusion, whereas mere toleration of it would not.

The integration of immigrants into a host society is a hotly-contested issue (Vermeulen, 2004), yet is generally regarded by policymakers throughout the EU as a legitimate objective of public policy-often with yet another nametag, "social cohesion," attached to it (CEC, 2003). However, the actual phenomenon of integration occurs regardless of public policy; its operation is non-transparent and with diverse mechanisms and areas of interaction, and is generally so complex as to yield an unlimited number of diverse analyses and explanations.

\section{DESIGN AND METHODOLOGY}

\section{Population of the study}

The population of the study consisted of all immigrant workers in service companies in Al Riyadh, Saudi Arabia. These total about 3,000 immigrants.

\section{Sample of the study}

The sample of the study consisted of 150 immigrants who were working in three service companies in $\mathrm{Al}$ Riyadh in 2012. A questionnaire was administered to them.

\section{Instruments of the study}

A questionnaire was administered to the immigrant workers at three service companies. The questionnaire was designed by the researcher and consists of 25 items. Variables such as gender, age, and educational level of the workers were included.

\section{Reliability of the instrument}

To ensure questionnaire reliability, the researcher administered the questionnaire to a pilot sample of 20 workers, who were excluded from the study sample, in the same companies from which the sample was chosen. There was a two-week period between the first and second time the questionnaire was administered. The researcher found the questionnaire reliable and suitable after he calculated its correlation coefficient.

\section{Procedures of the study}

A questionnaire on the problems immigrants face in service companies in Al Riyadh was administered to 150 immigrants. Thereafter, the researcher collected the questionnaires and data, which was analyzed statistically.

\section{Statistical analysis}

The results were analyzed for each question using suitable statistical methods such as mean and standard deviation. The researcher also used figures to further clarify the results. 


\section{FINDINGS OF THE STUDY}

The purpose of this study was to investigate the problems that immigrants working in service companies in Al Riyadh, Saudi Arabia, face from their own perspectives, and to understand the effect of the workers' gender, age, and educational level on their perspectives. A questionnaire was administered to 150 workers in three service companies in Al Riyadh. The means, standard deviations, and T-tests were used to analyze the results.

To answer the first question - immigrant workers' attitudes towards the problems they are facing-a questionnaire was distributed and means and standard deviations were calculated. Results are shown in Table 1.

Table 1. Immigrants' attitudes towards the problems they are facing at service companies in Al Riyadh

\begin{tabular}{|c|c|c|}
\hline No. & Mean & Std. Deviation \\
\hline Q1 & 4.14 & .840 \\
\hline Q2 & 4.17 & .853 \\
\hline Q3 & 3.19 & 1.054 \\
\hline Q4 & 3.22 & .981 \\
\hline Q5 & 4.14 & .896 \\
\hline Q6 & 3.15 & 1.189 \\
\hline Q7 & 3.27 & 1.202 \\
\hline Q8 & 4.20 & .998 \\
\hline Q9 & 3.21 & 1.316 \\
\hline Q10 & 4.05 & .974 \\
\hline Q11 & 4.53 & .768 \\
\hline Q12 & 2.90 & 1.199 \\
\hline Q13 & 3.64 & 1.317 \\
\hline Q14 & 2.92 & .937 \\
\hline Q15 & 4.02 & 1.076 \\
\hline Q16 & 4.38 & .864 \\
\hline Q17 & 3.45 & 1.214 \\
\hline Q18 & 3.03 & 1.029 \\
\hline Q19 & 4.18 & .869 \\
\hline Q20 & 4.36 & .810 \\
\hline Attitudes & 3.71 & .186 \\
\hline Valid N (list wise) & & \\
\hline
\end{tabular}

Table 1 shows that there are statistically significant differences in immigrants' attitudes towards the problems they are facing at service companies in Al Riyadh. It shows the results of the questionnaire that was distributed among 150 immigrant workers on their attitudes towards the problems they are facing. Means and standard deviations were calculated, and the results show that Question 11 had the highest mean of 4.53; Question 16 came next, with a mean of 4.38 .

The standard deviation for Question 11 was 0.768 , which is higher than $\alpha \leq 0,05$ and so is statistically significant. The standard deviation for Question 16 was nearly the same- 0.864 -which is also statistically significant.

To answer the second question about immigrants' attitudes and their gender, means and standard deviations were computed; Table 2 shows the results.

Table 2. Means, standard deviations, and t-test according to the gender variable

\begin{tabular}{cccccccc}
\hline & Gender & $\mathbf{N}$ & Mean & $\begin{array}{c}\text { Std } \\
\text { Deviation }\end{array}$ & t & df & Sig. (2-tailed) \\
\hline \multirow{2}{*}{ Attitudes } & Male & 60 & 3.62 & .149 & -5.373 & 164 & .000 \\
& Female & 90 & 3.77 & .186 & & & \\
\hline
\end{tabular}

Table 2 shows that there are statistically significant differences due to the gender variable. It shows the results of the questionnaire distributed among 150 immigrants about their attitudes towards the problems they are facing. Means and standard deviations were calculated, and the results show that male immigrant workers had a 
lower mean than female workers did-3.62 and 3.77, respectively. This indicates that the gender variable has an effect on immigrants' attitudes.

The standard deviation for male immigrants was 0.149 , which is higher than $\alpha \leq 0,05$ and so is statistically significant. The standard deviation for female immigrants was higher -0.186 - which is also statistically significant. Table 2, therefore, shows that there are statistically significant differences owing to the gender variable in favor of females.

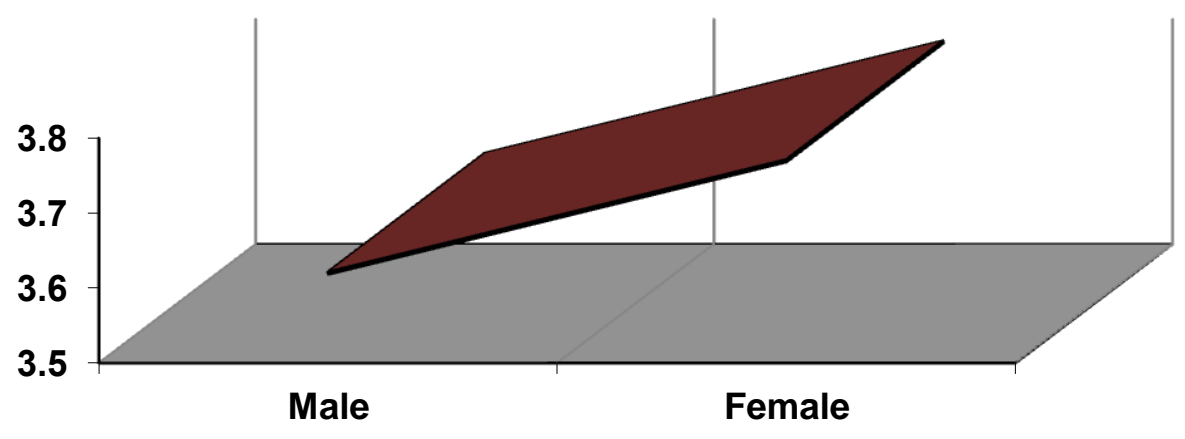

Figure 1. Means, standard deviations, and t-test according to the gender variable

Figure 1 shows that male immigrants have less negative attitudes towards the problems they are facing than female immigrants do.

To answer the third question about immigrants' attitudes and age, means and standard deviations were computed. Table 3 shows the results.

Table 3. Means, standard deviations, and t-test according to the age variable

\begin{tabular}{|c|c|c|c|c|c|c|c|}
\hline & Age & $\mathbf{N}$ & Mean & Std. Deviation & $\mathbf{t}$ & df & Sig. (2-tailed) \\
\hline \multirow{2}{*}{ Attitudes } & Less than 30 years old & 98 & 3.75 & .195 & 3.294 & 164 & .001 \\
\hline & 30 years old or above & 52 & 3.66 & .162 & & & \\
\hline
\end{tabular}

Table 3 shows that there are statistically significant differences owing to the age variable. It shows the results of the questionnaire distributed among 150 immigrants about their attitudes towards the problems they are facing. Means and standard deviations were calculated, and the results show that immigrants who are less than 30 years old had a higher mean than immigrants who are 30 years old or above -3.75 and 3.66 , respectively. This indicates that age has an effect on the immigrants' attitudes.

The standard deviation for immigrants who are less than 30 years old was 0.195 , which is higher than $\alpha \leq$ 0,05 and so is statistically significant. The standard deviation for immigrants who are 30 years old or above was lower- 0.162 - which is also statistically significant. Table 3, therefore, shows that there are statistically significant differences owing to the gender variable in favor of immigrants who are less than 30 years old. 


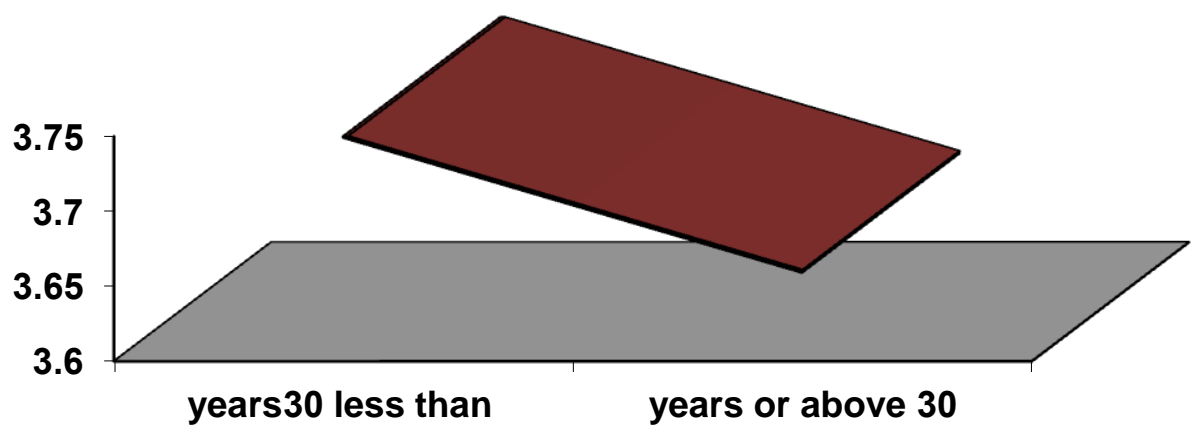

Figure 2. Means, standard deviations, and t-test according to the age variable

Figure 2 shows that immigrants who are less than 30 years old have a more negative attitude towards the problems they are facing than immigrants who are 30 years old or above.

To answer the fourth question about immigrants' attitudes and their educational level, means and standard deviations were computed. Table 4 shows the results.

Table 4. Means, standard deviations, and t-test according to educational level variable

\begin{tabular}{lllccccc}
\hline & Educational level & N & Mean & Std. Deviation & t & df & Sig. (2-tailed) \\
\hline \multirow{2}{*}{ Attitudes } & High school & 115 & 3.75 & .194 & 4.852 & 164 & .000 \\
& Bachelor's degree & 35 & 3.61 & .120 & & & \\
\hline
\end{tabular}

Table 4 shows that there are statistically significant differences owing to the educational level variable. It shows the results of the questionnaire that was distributed among 150 immigrants about their attitudes towards the problems they are facing. Means and standard deviations were calculated, and the results show that immigrants with only a high school education had a higher mean than immigrants with bachelor's degrees-3.75 and 3.61, respectively. This indicates that educational level has an effect on immigrants' attitudes.

The standard deviation for immigrants with only a high school education was 0.194 , which is higher than $\alpha$ $\leq 0,05$ and so is statistically significant. Standard deviation for immigrants with a bachelor's degree was lower0.120 - which is also not statistically significant. Table 4, therefore, shows that there are statistically significant differences owing to the academic level variable in favor of immigrants who have only a high school education. 


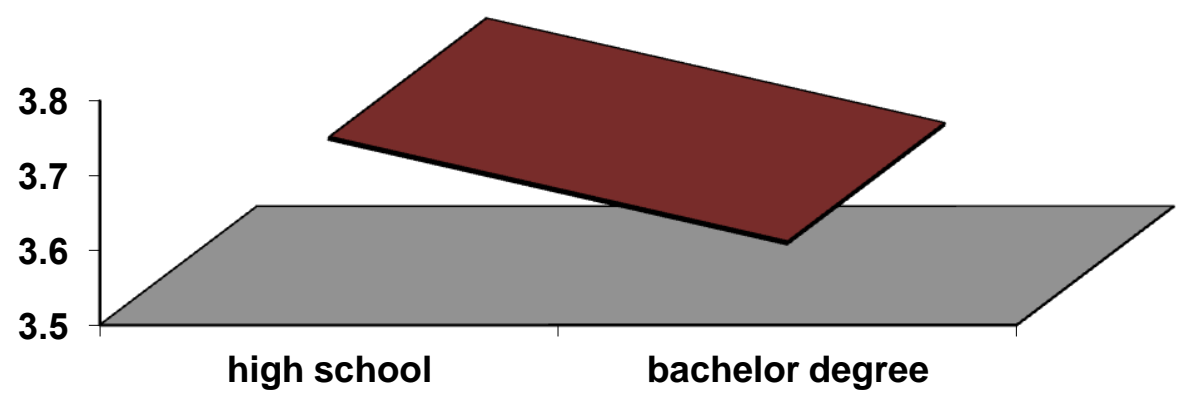

Figure 4. Means, standard deviations, and t-test according to the educational level variable

Figure 4 shows that immigrants with only a high school education have more negative attitudes towards the problems they are facing than immigrants' who have bachelor's degrees.

\section{CONCLUSION}

Immigrants face many problems in host countries. This study showed that immigrants who work in service companies in Saudi Arabia face many problems, and these problems differ from one individual to another according to many variables, including gender, age, and educational level. The researcher shed light on some of these problems, investigated the attitudes of immigrants, and clarified results using suitable statistical analyses.

\section{REFERENCES}

Alexander, M. (2003). Local policies towards migrants as an expression of Host-Stranger relations: A proposed typology. Journal of Ethnic and Migration Studies, 29(3).

Apitzsch, U. (2003). Gaining Autonomy in Self-employment Processes. International Review of Sociology, 13(1).

Alund, A. (2003). Self-employment of Non-privileged Groups as Integration Strategy. International Review of Sociology, 13(1).

CEC (2003). Communication from the Commission. On immigration, integration, and employment. COM (2003) 336 final, 3.6.2003.

Koff, H. (2002). Let's Talk: Dialogue Across Disciplines on Immigration and Integration Issues. Working Paper 60, Center for Comparative Immigration Studies, UCSD.

Kupferberg, F. (2003). The Established and the Newcomers: what makes immigrant and women entrepreneurs so special? International Review of Sociology, 13(1).

Segal, U. A. (2002). A framework for immigration: Asians in the United States. New York: Columbia University Press.

Vermeulen, H. (2004): Models and Modes of Immigrant Integration... and where does southern Europe fit? In C. Inglessi et al. (eds), Immigration and Integration in Northern versus Southern Europe. Athens: Netherlands Institute in Athens, pp. 27-39. 